\title{
Knowledge, opinions, and practices related to oral cancer prevention and oral mucosal examination among dentists in Moldova, Belarus and Armenia: a multi-country cross-sectional study
}

Olga Golburean 1*, Maria Helene Hagen², Diana Uncuta ${ }^{3}$, Marcela Tighineanu ${ }^{3}$, Gayane Manrikyan ${ }^{4}$, Izabella Vardanian ${ }^{4}$, Christoffer Andresen ${ }^{5}$, Bhavdeep Singh ${ }^{5}$, Tatiana Porosencova ${ }^{3}$, Irina Ivasiuc ${ }^{3}$, Olga Cheptanaru ${ }^{3}$, Marina Markaryan ${ }^{4}$, Natalia Shakavets ${ }^{6}$, Dipak Sapkota ${ }^{5}$, Tine Merete Søland ${ }^{5,7}$, Daniela-Elena Costea ${ }^{8, *^{*}}$ and Ferda Özkaya ${ }^{2}$

\begin{abstract}
Introduction: Moldova, Belarus, and Armenia are post-Soviet countries with a high rate of heavy smokers and a relatively high age-standardized incidence of oral cancer. However, to our knowledge, there is lack of available information on dentists' knowledge on prevention of oral cancer in the countries in question. Accordingly, this study aimed to assess the knowledge, opinions, and practices related to oral cancer prevention and oral mucosal examination among dentists in Moldova, Belarus, and Armenia.
\end{abstract}

Methods: This was a multi-country, cross-sectional study based on a self-administered questionnaire. A structured questionnaire was distributed to 3534 dentists (797 in Chisinau, Moldova, 1349 in Minsk, Belarus, and 1388 in Yerevan, Armenia). Dentists' knowledge about risk factors for oral cancer development and its clinical picture, current practices and opinions with regard to oral mucosal screening and oral cancer prevention, and their consistency to perform oral mucosal examination were assessed. A knowledge score ranging from 0 to 14 points was generated based on each dentist's answer to the questionnaire.

Results: A total of 1316 dentists responded, achieving an overall response rate of 37.2\% (34.5\% in Moldova; 52.3\% in Belarus; $24.2 \%$ in Armenia). Most dentists in the three countries correctly identified tobacco (83.8-98.2\%) and prior oral cancer lesions (84.0-96.3\%) as risk factors for oral cancer. Most dentists correctly identified leukoplakia as a lesion with malignant potential (68.7\% in Moldova; 88.5\% in Belarus; 69.9\% in Armenia), while erythroplakia was identified by much fewer in all three countries. Less than $52 \%$ of dentists identified the tongue, rim of tongue, and floor of mouth as the most common sites for oral cancer. The mean knowledge score for all countries combined was 7.5 \pm 2.7 .

\footnotetext{
*Correspondence: Golbureanolga94@gmail.com; Daniela.Costea@uib.no

${ }^{1}$ Centre for International Health, Faculty of Medicine, University

of Bergen, Bergen, Norway

${ }^{8}$ Department of Clinical Medicine, Center of Cancer Biomarkers CCBIO,

Faculty of Medicine, University of Bergen, Bergen, Norway

Full list of author information is available at the end of the article
}

(c) The Author(s) 2021. Open Access This article is licensed under a Creative Commons Attribution 4.0 International License, which permits use, sharing, adaptation, distribution and reproduction in any medium or format, as long as you give appropriate credit to the original author(s) and the source, provide a link to the Creative Commons licence, and indicate if changes were made. The images or other third party material in this article are included in the article's Creative Commons licence, unless indicated otherwise in a credit line to the material. If material is not included in the article's Creative Commons licence and your intended use is not permitted by statutory regulation or exceeds the permitted use, you will need to obtain permission directly from the copyright holder. To view a copy of this licence, visit http:/creativecommons.org/licenses/by/4.0/ The Creative Commons Public Domain Dedication waiver (http:/creativecommons.org/publicdomain/zero/1.0/) applies to the data made available in this article, unless otherwise stated in a credit line to the data. 
The most commonly reported barriers to perform oral mucosal examination were lack of training, knowledge, and experience.

Conclusions: This study highlights the need for improved oral cancer-related education and training on oral mucosal examination for dentists in Moldova, Belarus, and Armenia. Such skills are essential to enhance oral cancer prevention and to improve the prognostic outcome by early detection.

Keywords: Oral cancer, Prevention, Knowledge, Opinion, Practice, Dentist, Moldova, Belarus, Armenia

\section{Introduction}

Oral squamous cell carcinoma (OSCC), a malignancy arising from the surface epithelium of oral cavity, accounts for more than $90 \%$ of all oral cancers [1]. As the estimated 5-year survival rate for OSCC significantly decreases from approximately $85 \%$ if detected at early stages (I and II) to $40 \%$ if detected at advanced stages (III and IV) [2], its early detection is crucial. It is consequently essential that oral health practitioners understand the importance of conducting a thorough oral mucosal examination for malignant and potentially malignant lesions as part of their routine clinical assessments, including the examination of high-risk areas such as the rim of the tongue and the floor of the mouth [3, 4]. Having a good knowledge of the risk factors of OSCC such as tobacco use, excessive alcohol consumption, exposure to ultraviolet radiation, a past positive OSCC history, advanced age, and a poor diet/nutrition may also increase the awareness of the dentists and thereby detection of OSCC at an early stage [5-9].

Several studies from Europe, North America, Australia, and the Middle East identified gaps in dentists' knowledge related to the risk factors, clinical presentation, and diagnostic procedures of oral cancer, as well as to the guidelines and protocols for referral of patients with lesions with malignant potential $[3,10-20]$. Thus, there is a worldwide need for improved knowledge and education of oral health practitioners on early diagnosis and referral of OSCC $[9,21,22]$. This will have an overall positive impact on improving patients' quality of life, decreasing treatment costs, and reducing morbidity and mortality rates.

Moldova, Belarus, and Armenia are all post-Soviet nations with a high rate of heavy smokers in their populations and a relatively high age-standardized incidence rate of OSCC [23]. For Moldova, the prevalence of adult smokers was 25.3\% in 2013 (men: 43.6\%; women: 5.6\%) [24], and oral cancer accounted for $1.9 \%$ of all new cancer cases and for $1.9 \%$ of all cancer-related deaths in 2018 [25]. Interestingly, there has been a 22\% increase in oral cancer-related mortality in women in Moldova between 1990-1994 and 2005-2007 [23]. In Belarus, the prevalence of adult smokers in 2013 was $25.9 \%$ (men: 48.6\%; women: 9.7\%) [26], and even more alarming is the finding of a $61 \%$ increase in oral cancer-related mortality in women between 2000-2003 and 2007 [23]. In 2018, oral cancer accounted for $1.6 \%$ of all new cancer cases and for $1.7 \%$ of all cancer-related deaths in Belarus [27]. For Armenia, where the prevalence of adult smokers was $25.4 \%$ in 2012 (men: 50.9\%; women: 3.2\%) [28], oral cancer accounted for $0.50 \%$ of all new cancer cases and for $0.41 \%$ of all cancer-related deaths in 2018 [29]. Moldova and Belarus also have very high levels of alcohol consumption, with a per capita alcohol consumption of 15.2 $\mathrm{L}$ for Moldova and 11.2 L for Belarus in 2016 compared to $5.5 \mathrm{~L}$ for Armenia and $9.8 \mathrm{~L}$ for the overall European region [30].

To our knowledge, there is lack of available information on dentists' knowledge on oral cancer in the countries in question. Accordingly, the aim of this study was to assess the knowledge, opinions, and practices related to oral cancer prevention and oral mucosal examination among dentists in the capital cities of Moldova (Chisinau), Belarus (Minsk), and Armenia (Yerevan).

\section{Materials and methods Study design}

This multi-country cross-sectional study was conducted using a structured, self-administered questionnaire that was distributed to all dental clinics in Chisinau, Minsk and Yerevan. The study received ethical approval from the Norwegian Centre for Research Data (Project No. 471282 and 57451), and national ethical committees in Moldova, Belarus, and Armenia. Participation in this study was voluntary, and written informed consent was obtained from all participating dentists. The data collection period was from June 2018 to September 2019.

All actively practicing dentists in Minsk, Chisinau and Yerevan were invited to participate to the study. Prior to data collection, a list of 216 dental clinics in Minsk, 233 in Chisinau, and 130 in Yerevan was obtained from local coordinators, who were highly knowledgeable about local regulations and practices in dentistry. All dental clinics on the list were visited by the responsible investigator(s) who explained the purpose of the study and personally distributed the questionnaire to the consenting dentists. The responsible investigator(s) returned to each dental 
clinic after 1-3 days from the initial visit to collect the completed questionnaires.

\section{Questionnaire}

The questionnaire used in the present study was developed based on previous studies conducted elsewhere [31-34]. The questionnaire was first prepared in English, and then translated into the local languages in the respective countries (Romanian, Russian, and Armenian), following a standardized forward-backward procedure. A pilot version of the questionnaire was tested on 10 dentists from each of the three countries during December 2017. Based on the pilot survey results and feedback from academicians at the collaborative institutions, necessary adjustments of the questionnaire were made.

The questionnaire, which was self-explanatory and closed-ended, consisted of 70 items, divided into six different parts: (1) personal data, (2) oral hygiene, dietary behavior, and utilization of dental services, (3) competency and orientation in preventive care, (4) preventive knowledge, (5) preventive practice for patients and (6) oral mucosal screening and oral cancer prevention. The later part on oral mucosal screening and oral cancer prevention was used in the analysis of the present study (Additional file 1). Clinical practices and opinions related to oral mucosal examination and oral cancer prevention, dentists' barriers to oral mucosal examination, knowledge of oral cancer risk factors and diagnostic procedures, and oral cancer information sources were assessed. Response formats included a 5-point Likert scale, several correct answers in case of multiple-choice questions, and a 'yes', 'no', and 'do not remember' format. Questions (22-30) were used to assess dentists` level of knowledge regarding oral cancer. For each correct answer on the questions (22-30), a score of " 1 " was given. Dentists ' level of knowledge was constructed based on the total number of points accumulated (ranging from 0 to 14). The present study used the mean score as cut-off point. The mean \pm SD knowledge score for all countries combined was $7.5 \pm 2.7$ (range, 0-14). Knowledge score was dichotomized into $0=$ lower score of knowledge $(0-7)$, and $1=$ higher score of knowledge (8-14).

\section{Data analysis}

Data were analyzed separately for each country. All analyses were performed using IBM SPSS Statistics version 25.0 (IBM Corporation, Armonk, NY, USA). Descriptive statistics were reported using means and standard deviations (SD) for continuous variables and frequency with percentages for categorical variables. Chi-square tests were employed to assess bivariate relationships. Multivariable logistic regression analysis (adjusted odds ratio and 95\% confidence intervals) was used to detect associations between the dentists' knowledge score and their sociodemographic and work characteristics. The results that were statistically significant in the unadjusted analysis were included in the model. The analysis for the associations was done with merged data (from all countries). The level of statistical significance was defined as $\mathrm{p}<0.05$.

\section{Results}

\section{Characteristics of the study participants}

Of the 3534 dentists (797 in Moldova, 1349 in Belarus, and 1388 in Armenia) invited to participate, 1316 responded, giving an overall response rate of $37.2 \%$. Out of the three countries, Belarus had the highest response rate at $52.3 \%(705 / 1349)$ compared to $34.5 \%(275 / 797)$ for Moldova and 24.2\% (336/1388) for Armenia.

The sociodemographic and work characteristics of the study participants are presented in Table 1. Participants' characteristics were overall comparable across the three countries, with some minor differences. For instance, in Belarus, the study population was predominantly male (79.1\%), whereas a balanced number of women and men was found for Moldova and Armenia. Moreover, most dentists in Moldova (62.2\%) and in Armenia (78.9\%) were working exclusively in private clinics, while in Belarus, the majority were working in the public sector $(60.9 \%)$. Only $8.0 \%$ of dentists in Moldova answered that they worked solo compared to $29.5 \%$ in Belarus and $42.3 \%$ in Armenia. More than half of dentists in Moldova (57.1\%) and Armenia (61.6\%) were general dental practitioners, whereas in Belarus, more than one-third (34.3\%) were identified as restorative dentists or endodontists.

\section{Knowledge of the clinical diagnosis of and risk factors for oral cancer}

As shown in Fig. 1, most participants correctly identified tobacco (83.8-98.2\%) and prior oral cancer lesions (84.0$96.3 \%)$, as risk factors for oral cancer. A lower percentage of dentists (50-69.7\%) correctly identified abusive use of alcohol as a risk factor (Fig. 1).

When asked about the most common sites for oral cancer (Table 2), the tongue was correctly listed by $40.0 \%$ of dentists in Moldova, $51.8 \%$ in Belarus and $43.5 \%$ in Armenia. The floor of the mouth was also correctly identified by $31.6 \%$ of dentists in Moldova, $43.3 \%$ in Belarus, and $22.9 \%$ in Armenia. Less than $30 \%$ of the dentists were able to identify the rim of the tongue as one of the most common sites for oral cancer. Leukoplakia was considered the most common oral potentially malignant lesion in all three countries, listed by $68.7 \%, 88.5 \%$ and $69.9 \%$ of the dentists in Moldova, Belarus and Armenia, respectively. Erythroplakia was listed as the second lesion most likely to be oral potentially malignant lesion in Moldova 
Table 1 Sociodemographic and work characteristics of study participants by country

\begin{tabular}{|c|c|c|c|}
\hline & Moldova $(\mathrm{N}=275)$ & Belarus $(\mathrm{N}=705)$ & Armenia $(\mathrm{N}=336)$ \\
\hline Mean $\pm S D$ age (years) & $40.3 \pm 11.9$ & $40.6 \pm 11.2$ & $38.2 \pm 11.3$ \\
\hline \multicolumn{4}{|l|}{ Age group (years) } \\
\hline 20-39 & $139(50.5)$ & $331(47.0)$ & $191(56.8)$ \\
\hline$\geq 40$ & $121(44.0)$ & $363(51.5)$ & $125(37.2)$ \\
\hline \multicolumn{4}{|l|}{ Gender } \\
\hline Male & $141(51.3)$ & $558(79.1)$ & $169(50.3)$ \\
\hline Female & $134(48.7)$ & $143(20.3)$ & $167(49.7)$ \\
\hline \multicolumn{4}{|l|}{ Years of practice } \\
\hline$<5$ & $54(19.6)$ & $93(13.2)$ & $65(19.3)$ \\
\hline $5-15$ & $87(31.6)$ & $233(33.0)$ & $120(35.7)$ \\
\hline$>15$ & $110(40.0)$ & $358(50.8)$ & $106(31.5)$ \\
\hline \multicolumn{4}{|l|}{ Work sector } \\
\hline Private & $171(62.2)$ & $162(23.0)$ & $265(78.9)$ \\
\hline Public/university & $74(26.9)$ & $429(60.9)$ & $38(11.3)$ \\
\hline Both & $28(10.2)$ & $113(16.0)$ & $23(6.8)$ \\
\hline \multicolumn{4}{|l|}{ Practice setting } \\
\hline Solo & $22(8.0)$ & $208(29.5)$ & $142(42.3)$ \\
\hline Non-solo & $252(91.6)$ & $456(64.7)$ & $184(54.8)$ \\
\hline \multicolumn{4}{|l|}{ Specialty } \\
\hline General dentistry & $157(57.1)$ & $182(25.8)$ & $207(61.6)$ \\
\hline Restorative/endodontics & $19(6.9)$ & $242(34.3)$ & $12(3.6)$ \\
\hline Prosthodontics & $16(5.8)$ & $84(11.9)$ & $30(8.9)$ \\
\hline Oral surgery & $14(5.1)$ & $34(4.8)$ & $19(5.7)$ \\
\hline Pediatrics/orthodontics & $11(4.0)$ & $135(19.1)$ & $23(6.8)$ \\
\hline Periodontics & $4(1.5)$ & $15(2.1)$ & $4(1.2)$ \\
\hline Oral pathology & $3(1.1)$ & $11(1.6)$ & $3(0.9)$ \\
\hline \multicolumn{4}{|l|}{ Main patient group } \\
\hline Children (0-18) & $7(2.5)$ & $130(18.4)$ & $11(3.3)$ \\
\hline Adults & $118(42.9)$ & $370(52.5)$ & $139(41.4)$ \\
\hline Mixed & $148(53.8)$ & $195(27.7)$ & $174(51.8)$ \\
\hline
\end{tabular}

Data are expressed as $n(\%)$, unless otherwise indicated. Percentages are calculated as n/N

Some figures are subject to missing data; values may not add up to total sample

SD standard deviation

and Belarus, while in Armenia, aphthous ulceration was listed as the second one. The most commonly listed clinical properties of early cancer lesions were small, painless and indurated ulcerations (33.9-63.4\%) followed by small, painless white area (29.2-34.5\%).

The mean $\pm S D$ score for knowledge of the risk factors and clinical diagnosis of oral cancer was $7.3 \pm 2.9$, $8.2 \pm 2.2$, and $6.2 \pm 2.8$ in Moldova, Belarus and Armenia, respectively. The mean \pm SD knowledge score for all countries combined was $7.5 \pm 2.7$ (range, 0-14). Multivariable logistic regression analyses revealed that there was a significant association $(\mathrm{p}<0.05)$ between dentists' knowledge score and country as well as gender; female dentists and dentists from Belarus were significantly more likely to have a higher knowledge of the risk factors and clinical diagnosis of oral cancer (Table 3 ).

\section{Practices related to oral cancer prevention and early detection}

Regarding dentists' practices related to oral cancer prevention and early oral cancer detection, the majority reported that they examine all new patients $(88.0 \%$ in Moldova, $94.6 \%$ in Belarus, and $72.0 \%$ in Armenia) as well as all recall patients (87.0\% in Moldova, $84.2 \%$ in Belarus, and $67.3 \%$ in Armenia) for oral mucosal lesions. Moreover, most dentists $(81.5 \%$ in Moldova, $77.3 \%$ in Belarus, and $87.1 \%$ in Armenia) reported that when taking a patient's medical history, they ask about current/previous 


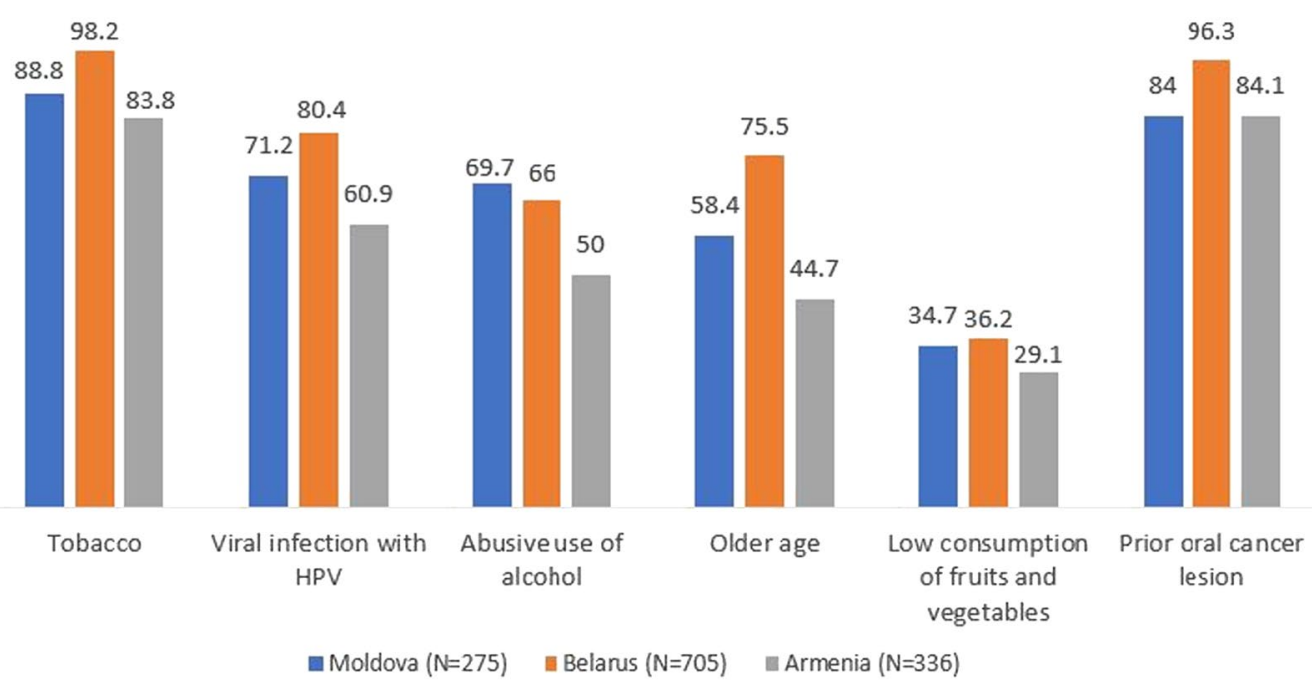

Fig. 1 Percentage of dentists that correctly identified the risk factors for oral cancer

Table 2 Dentists' knowledge about the clinical diagnosis of oral cancer

\begin{tabular}{|c|c|c|c|}
\hline & Moldova ( $\mathrm{N}=275)$ & Belarus $(\mathrm{N}=705)$ & Armenia $(\mathrm{N}=336)$ \\
\hline \multicolumn{4}{|l|}{ Most common sites for oral cancer } \\
\hline All sites equally & $93(33.8)$ & $156(22.1)$ & $90(26.8)$ \\
\hline FloFor of the mouth & $87(31.6)$ & $305(43.3)$ & $77(22.9)$ \\
\hline Buccal/lip mucosa & $107(38.9)$ & $268(38.0)$ & $134(39.9)$ \\
\hline Hard palate & $55(20.0)$ & $79(11.2)$ & $92(27.4)$ \\
\hline Soft palate & $51(18.5)$ & $73(10.4)$ & $47(14.0)$ \\
\hline Retromolar region/palatopharyngeal arches & $48(17.5)$ & $120(17.0)$ & $32(9.5)$ \\
\hline Tongue & $110(40.0)$ & $365(51.8)$ & $146(43.5)$ \\
\hline Rim of tongue & $79(28.7)$ & $167(23.7)$ & $82(24.4)$ \\
\hline Do not know & $34(12.4)$ & $49(7.0)$ & $29(8.6)$ \\
\hline \multicolumn{4}{|l|}{ Oral potentially malignant disorders } \\
\hline Morbus Crohn & $27(9.8)$ & $79(11.2)$ & $14(4.2)$ \\
\hline Erythroplakia & $84(30.5)$ & $346(49.1)$ & $69(20.5)$ \\
\hline Blue nevus & $45(16.4)$ & $167(23.7)$ & $40(11.9)$ \\
\hline Leukoplakia & $189(68.7)$ & $624(88.5)$ & $235(69.9)$ \\
\hline Aphtha & $55(20.0)$ & $63(8.9)$ & $135(40.2)$ \\
\hline Do not know & $34(12.4)$ & $47(6.7)$ & $43(12.8)$ \\
\hline \multicolumn{4}{|l|}{ Clinical properties of an early cancer lesion } \\
\hline Small, painless white area & $94(34.2)$ & $243(34.5)$ & $98(29.2)$ \\
\hline Small, painless red area & $65(23.6)$ & $125(17.7)$ & $70(20.8)$ \\
\hline Small, painless, indurated ulceration & $155(56.4)$ & $447(63.4)$ & $114(33.9)$ \\
\hline Small, painful, indurated ulceration & $49(17.8)$ & $189(26.8)$ & $86(25.6)$ \\
\hline Do not know & $39(14.2)$ & $19(2.7)$ & $60(17.9)$ \\
\hline
\end{tabular}

Data are expressed as $n$ (\%). Percentages are calculated as $n / N$

The underlined and italicized responses represent the correct answers 
Table 3 Proportion of dentists with a knowledge score $\geq 8$, and multivariate association between dentists' characteristics and the knowledge score

\begin{tabular}{lll}
\hline & $\%$ & Adjusted OR (95\% Cl) \\
\hline Country & & \\
$\quad$ Moldova & 51.2 & 1 \\
Belarus & 64.7 & $1.5(1.1-2.1)^{*}$ \\
$\quad$ Armenia & $31.5^{*}$ & $0.4(0.3-0.6)^{*}$ \\
Gender & & \\
$\quad$ Female & 59.1 & 1 \\
Male & $43.8^{*}$ & $0.7(0.5-0.9)^{*}$ \\
$\quad$ Work sector & & \\
$\quad$ Private & 46.4 & 1 \\
$\quad \begin{array}{l}\text { Public/university } \\
\text { Both }\end{array}$ & 60.8 & $1.0(0.8-1.3)$ \\
& $58.5^{*}$ & $1.1(0.7-1.6)$
\end{tabular}

Chi-square test; $C l$ confidence interval, $O R$ odds ratio * $p<005$

use of tobacco. By contrast, only $36.5 \%$ of dentists in Belarus reported that they ask patients about current/ previous use of alcohol, while in Moldova and Armenia, this percentage was at $57.0 \%$ and $64.2 \%$, respectively.

When asked if respondents had ever detected a suspicious lesion for oral cancer, $50.7 \%$ of dentists in Moldova, 82.7\% in Belarus and $32.0 \%$ in Armenia confirmed that they had. More than two-thirds of dentists in Belarus and Armenia and more than half in Moldova have referred suspected oral cancer patients to a specialist. Less than $30 \%$ of the dentists reported that they had taken a biopsy of the oral mucosa (Table 4).

The vast majority of dentists agreed or strongly agreed that it is the role of the dentist to perform oral mucosal examination $(90.6 \%$ in Moldova, $98.6 \%$ in Belarus, and $70.6 \%$ in Armenia). Only $48.4 \%$ of dentists in Belarus agreed or strongly agreed that they can influence a patient to reduce/quit smoking or drinking alcohol, while in Moldova and Armenia, this percentage was at $67.2 \%$ and $60.4 \%$, respectively.

\section{Perceived barriers to perform oral mucosal examination}

The most commonly listed barriers to perform oral mucosal examination in all three countries were the lack of training, knowledge, and experience (Fig. 2). Moreover, in Armenia, $63.3 \%$ of dentists identified the lack of financial incentives as a barrier for performing oral mucosal examination, while in Moldova and Belarus, fewer dentists considered it as a barrier.

\section{Discussion}

As dentists should play a key role in oral cancer prevention and early detection, they need to possess a thorough knowledge about oral cancer, its clinical signs and symptoms, and its risk factors. To the best of our knowledge, this is the first study to assess the knowledge, opinions, and practices of dentists toward oral cancer prevention and oral mucosal examination in Moldova, Belarus, and Armenia.

Overall, participants' characteristics were comparable across the three countries. However, a striking difference between the three countries was that more than $60 \%$ of dentists in Moldova and almost $80 \%$ in Armenia were working exclusively in the private sector, while in Belarus, more than $60 \%$ were employed in the public sector. Indeed, in Armenia, and especially in Yerevan, the vast majority of dental services and dental equipment support have been privatized [35]. Anecdotal evidence has

Table 4 Dentists' practices when detecting a suspicious lesion

\begin{tabular}{lccc}
\hline & Moldova $(\mathbf{N}=\mathbf{2 6 8})$ & Belarus $(\mathbf{N}=\mathbf{7 0 4})$ & Armenia (N=328) \\
\hline $\begin{array}{l}\text { Ever detected a suspicious lesion for oral cancer } \\
\text { Yes }\end{array}$ & $136(50.7)$ & $582(82.7)$ & $105(32.0)$ \\
No & $111(41.4)$ & $88(12.5)$ & $198(60.4)$ \\
Do not remember & $20(7.5)$ & $33(4.7)$ & $25(7.6)$ \\
Referred to specialist & & & $239(72.9)$ \\
Yes & $156(58.2)$ & $526(74.7)$ & $62(18.9)$ \\
No & $93(34.7)$ & $117(16.6)$ & $27(8.2)$ \\
Do not remember & $18(6.7)$ & $58(8.2)$ & \\
Performed biopsy of oral mucosa & & & $98(29.9)$ \\
Yes & $47(17.5)$ & $68(12.5)$ & $214(65.2)$ \\
No & $216(80.6)$ & $907(86.2)$ & $16(4.9)$ \\
Do not remember & $5(1.9)$ & $9(1.3)$ & \\
\hline
\end{tabular}

Data are expressed as $n$ (\%). Percentages are calculated as $n / N$

Some figures are subject to missing data; values may not add up to total sample 


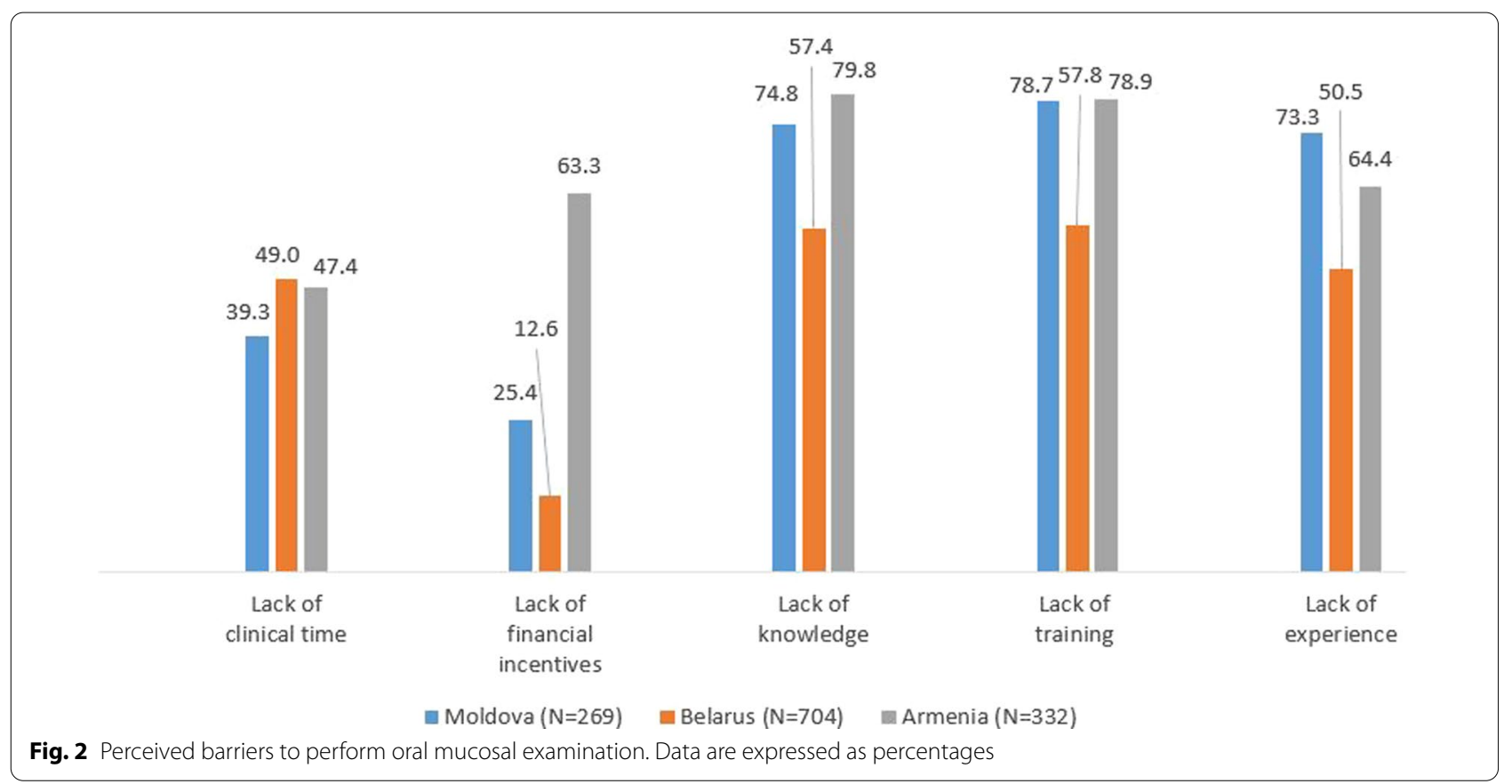

also suggested that because of low incentives and salaries, many dentists in Armenia have moved from the public to the private sector [35]. Similarly, in Moldova, most oral health care is provided privately [36]. By contrast, in Belarus, state dental clinics are predominant, as private dentistry is not well-developed due to the underdevelopment or lack of insurance systems [37].

The study results showed that more than $83 \%$ of respondents were aware of tobacco as a risk factor for oral cancer. By contrast, abusive use of alcohol was less commonly identified as a risk factor. In addition, only $36.5 \%$ of dentists in Belarus noted that they ask patients about their current/previous use of alcohol. These findings are concerning, as a strong association between abusive use of alcohol and oral cancer has been noted [38]. This association highlights the importance of dental practitioners' awareness on abusive alcohol use as a risk factor, particularly in countries with a high alcohol consumption such as Moldova and Belarus [30]. Thus, it is important that dentists in these countries provide adequate information to their patients about the impact of alcohol on oral cancer.

Viral infections with high-risk human papillomavirus (HPV) were also identified as a risk factor for oral cancer by a relatively high percentage of dentists in the present study, although HPV is mainly known as a risk factor for oropharyngeal cancers [39] and not for oral cancers [40]. While HPV has been identified in around $70-90 \%$ of oropharyngeal cancer cases, the average prevalence of HPVpositive oral cancer was estimated at $4.4 \%$ in a systematic review evaluating the prevalence of HPV-positive OSCC using E6/E7 mRNA expression analysis [40]. This low prevalence of HPV-positive OSCC challenges the view that HPV is a possible etiological factor in oral cancer. Nevertheless, due to the proximity of the oropharynx to the oral cavity and that the upper part of oropharynx should be examined by dentists, dentists should know about the association between HPV and oropharyngeal cancer [39].

At an early stage, oral cancer is usually asymptomatic and might be difficult to detect due to clinical similarities and the size of the lesion. For this reason, dental practitioners must be conscious about what to look for and where to look in order to detect oral cancer at an early stage $[7,41,42]$. The mobile/anterior $2 / 3$ of the tongue, the lateral surface of the tongue, and floor of the mouth are considered as the most common sites for oral cancer [43]. All three sites were correctly identified as the most common locations for oral cancer by less than $52 \%$ of the study population. By contrast, a recent systematic review measuring knowledge, attitudes, and practices regarding OSCC among dental practitioners revealed a good level of knowledge with regard to the common high-risk sites of oral cancer development such as tongue (up to $81 \%$ ) and floor of the mouth (up to 86\%) [9]. Leukoplakia and erythroplakia are the most common oral potentially malignant disorders (OPMDs) [44]. Leukoplakia was correctly identified by most of the dentists in all three countries. The respondents appeared to be less familiar with erythroplakia, so that it was correctly identified by only 
$30 \%, 49 \%$ and $20 \%$ of dentists in Moldova, Belarus and Armenia, respectively. Looking at similar studies, $87 \%$ of dentists in Yemen reported leukoplakia and erythroplakia as OPMDs [19]. An interesting point is that in Armenia, aphthous ulceration was incorrectly identified as an OPMD by $40.2 \%$ of the dentists. Aphthous ulceration in most cases is a harmless yellowish-white lesion and the outbreak heals within 7-14 days [45].

The most common OPMDs present clinically as small, painless, red or white, as well as ulcerations with coarseness [4]. Small, painless, indurated ulceration was correctly identified as a clinical property of an early oral cancer lesion by $33.9-63.4 \%$ of the dentists, and small, painless white or red by less than $35 \%$ of dentists in all three countries. In a study from Sudan, $80.5 \%$ of dentists correctly identified "white or red areas" as a marker of early oral cancer lesions, and more than $80 \%$ correctly reported that oral cancer at an early stage is usually painless [46]. This is in contrast to an Iranian study in which around $30 \%$ of dentists considered small, painless and red lesions as an early sign of oral cancer [47]. A range in the level of dentists' knowledge by country of practice was similarly noted in the present study, which might be related to different educational backgrounds, different training opportunities, and different professional environments.

With regard to oral mucosal examination, most dentists included in this study reported that they provide oral mucosa examination to all new and recall patients. Although these results are encouraging, they warrant caution, as with the questionnaire used in the present study it is not possible to determine the accuracy of oral mucosal examination. Data from the study conducted in Iran revealed that approximately $38 \%$ of dentists performing oral mucosa examination did not properly examine the tongue. Only $40 \%$ of them inspected the area under the tongue and only $15 \%$ examined the rim of the tongue [47].

Our study found that a high percentage of dentists in Belarus, and to a lesser extent in Moldova, have already detected a suspicious lesion for oral cancer. By contrast, most dentists have never performed a biopsy of oral mucosa throughout their career. This suggests, that when detecting a suspicious lesion, dentists tend to refer the patient to an appropriate specialist for an examination and biopsy such as an oral surgeon or an oral pathologist. Indeed, oral cancer is best managed by specialists with advanced training in oral pathology or oral surgery [33]. This practice is in line with the previous study from Iran [47], and with a study from the United Arab Emirates in which only $9.9 \%$ of dentists reported feeling comfortable performing a biopsy [48]. As clinical properties of an early cancer lesion are usually more obvious at an advanced stage, biopsy and histopathological examination can help diagnose an early-stage cancer $[4,49,50]$. Among the different dental specialties, pediatric dentists are the least likely to see a suspicious lesion for oral cancer.

Most of the participants commonly listed lack of training, knowledge, and experience as the main barriers to perform oral mucosa examination. In studies from Yemen [19] and Jordan [51], more than $80 \%$ of dentists perceived their knowledge about oral cancer as not up to date, which reveals the importance of continuous education on oral cancer. Educational interventions may be beneficial for dentists in all three studied countries and possibly reduce some of the barriers mentioned by the participants of the present study. Perceived barriers for performing oral mucosa examination were very similar between the countries, except for the lack of financial incentives that was largely reported as a barrier in Armenia. Unfortunately, in Armenia, low wages and difficult work conditions have been extensively reported for dentists and other dental health professionals working in both the public and the private sector [35].

As in many other surveys, this study has some limitations, primarily its relatively low response rate (37.2\%). However, the response rate in the present study was higher than that reported in previous similar studies $(<30 \%)$ [3, 52]. Nevertheless, the response rate might be attributed to the questionnaire length, as it was part of a more comprehensive questionnaire on prevention of oral diseases and consisted of 70 questions in total. This may have been interpreted as cumbersome and could have been a reason for reluctance to participate in the study. The low response rate, especially in Moldova and Armenia, may have led to non-response bias. However, we believe that the extent of differences between responders and non-responders in our study is narrow, given the broad representation of dentists (working in both the private and the public sectors) from different dental specialties [52]. In addition, the lists of dental clinics, which were obtained from the local coordinators, might have been somewhat outdated, hence possibly excluding certain new clinics. Moreover, since the study was based on a self-administered questionnaire, potential biases caused by self-reporting (i.e., recall bias and social desirability bias) cannot be excluded. To minimize social desirability bias, anonymous questionnaires were used in the present study. Furthermore, since participation in this study was voluntary, selection bias related to personal interests of clinicians cannot be ruled out. Lastly, since this study was restricted to the capital cities of Moldova, Belarus and Armenia, it is challenging to generalize these results to other parts of the country as well as to other countries. Nevertheless, our study had several strengths, including 
its large and multinational sample size, the very few missing data, and its novelty. This study also addresses an important health issue that challenges dentists in these three post-Soviet nations.

\section{Conclusions}

This cross-sectional study conducted among dentists in Moldova, Belarus, and Armenia highlights strengths as well as gaps in dentists' knowledge and practices related to oral cancer prevention and early detection. Data from the current study can be used as a foundation for future educational programs for dentists and can help reinforce the dental curriculum in order to enhance awareness and knowledge related to oral cancer prevention.

\section{Abbreviations \\ Cl: Confidence interval; HPV: Human papillomavirus; OPMD: Oral potentially malignant disorder; OR: Odds ratio; OSCC: Oral squamous cell carcinoma; SD:} Standard deviation.

\section{Supplementary Information}

The online version contains supplementary material available at https://doi. org/10.1186/s12903-021-02011-2.

Additional file 1. Questionnaire used in this study

\section{Acknowledgements}

The authors would like to thank all the dentists in Moldova, Belarus, and Armenia, for taking their time to participate in this study; it is self-explanatory that without your cooperation, this study could not be realized. The authors also express their gratitude to the cooperation of the University authorities in Moldova, Belarus, and Armenia and for their guidance throughout the fieldwork.

\section{Authors' contributions}

OG collected data from the dentists in the countries studied, analyzed the results, and drafted this manuscript. MH, DU, MT, PT, II and OC participated in the data collection in Moldova. GM, IV, BS, and CA participated in the data collection in Armenia. DEC was the coordinator of the project, designed the study, corrected and revised this manuscript. FÖ designed the study, was involved in data analysis, corrected and revised this manuscript. DU was involved in organizing fieldwork in Moldova. MM and GM were involved in organizing fieldwork in Armenia. NS was involved in organizing fieldwork in Belarus. TMS and DS were supervising and coordinating the data collection performed by OG, GM, IV, BS, and CA in Armenia. All authors contributed to the writing and editing of the manuscript, read and approved the final version of this manuscript. All authors read and approved the final manuscript.

\section{Funding}

This study was funded by the Norwegian Centre for International Cooperation in Education (CPEA-LT-2016/10106) and Norges Forskningsråd (22325).

\section{Availability of data and materials}

The datasets used for the current study are available from the corresponding author on reasonable request.

\section{Declarations}

\section{Ethics approval and consent to participate}

The project received ethical approval from the Norwegian Centre for Research Data (NSD) (Project No: 471282 and 57451) and national ethical committees in Moldova, Belarus and Armenia. The study was conducted according to the
Helsinki Declaration. The questionnaire was anonymous, and participation was voluntary. The participants of the study received written and verbal information. Participants were free to withdraw from the study at any point, without justifying. Before enrollment, an individual written consent was obtained from all participants.

\section{Consent for publication}

Not applicable.

\section{Competing interests}

The authors declare that they have no competing interests.

\section{Author details}

${ }^{1}$ Centre for International Health, Faculty of Medicine, University of Bergen, Bergen, Norway. ${ }^{2}$ Department of Clinical Dentistry, Faculty of Medicine, University of Bergen, Bergen, Norway. ${ }^{3}$ Department of Stomatological Propedeutics "Pavel Godoroja", Faculty of Stomatology, State University of Medicine and Pharmacy "Nicolae Testemițanu", Chisinau, Moldova. ${ }^{4}$ Department of Therapeutic Stomatology, Faculty of Stomatology, Yerevan State Medical University, Yerevan, Armenia. ${ }^{5}$ Institute of Oral Biology, Faculty of Dentistry, University of Oslo, Oslo, Norway. ${ }^{6}$ Department of Pediatric Dentistry, Faculty of Dentistry, Belarusian State Medical University, Minsk, Belarus. ${ }^{7}$ Department of Pathology, Rikshospitalet, Oslo University Hospital, Oslo, Norway. ${ }^{8}$ Department of Clinical Medicine, Center of Cancer Biomarkers CCBIO, Faculty of Medicine, University of Bergen, Bergen, Norway. ${ }^{9}$ Department of Pathology, Haukeland University Hospital, Bergen, Norway.

Received: 8 October 2021 Accepted: 29 November 2021

Published online: 18 December 2021

\section{References}

1. Mahjour F, Dambal V, Shrestha N, Singh V, Noonan V, Kantarci A, et al. Mechanism for oral tumor cell lysyl oxidase like-2 in cancer development: synergy with PDGF-AB. Oncogenesis. 2019;8(5):34.

2. Howlader N, Noone A, Krapcho M, Miller D, Brest A, Yu M, et al. SEER cancer statistics review, 1975-2017. National Cancer Institute Bethesda, MD. 2020.

3. Marino R, Haresaku S, McGrath R, Bailey D, McCullough M, Musolino $R$, et al. Oral cancer screening practices of oral health professionals in Australia. BMC Oral Health. 2017;17(1):151.

4. Bagan J, Sarrion G, Jimenez Y. Oral cancer: clinical features. Oral Oncol. 2010;46(6):414-7.

5. Mathur S, Conway DI, Worlledge-Andrew H, Macpherson LMD, Ross AJ. Assessment and prevention of behavioural and social risk factors associated with oral cancer: protocol for a systematic review of clinical guidelines and systematic reviews to inform primary care dental professionals. Syst Rev. 2015;4(1):184.

6. Malki AM, Raad SB, Abu-El-Ruz R. Prevention of oral cancer. In: Al Moustafa A-E, editor. Development of oral cancer: risk factors and prevention strategies. Cham: Springer; 2017. p. 193-217.

7. Edefonti V, Hashibe M, Ambrogi F, Parpinel M, Bravi F, Talamini R, et al. Nutrient-based dietary patterns and the risk of head and neck cancer: a pooled analysis in the International Head and Neck Cancer Epidemiology consortium. Ann Oncol. 2012;23(7):1869-80.

8. Bota JP, Lyons AB, Carroll BT. Squamous cell carcinoma of the lip-a review of squamous cell carcinogenesis of the mucosal and cutaneous junction. Dermatol Surg. 2017:43(4):494-506.

9. Coppola N, Mignogna MD, Rivieccio I, Blasi A, Bizzoca ME, Sorrentino $R$, et al. Current knowledge, attitudes, and practice among health care providers in OSCC awareness: systematic review and meta-analysis. Int J Environ Res Public Health. 2021;18(9):4506.

10. Hertrampf K, Wenz HJ, Koller M, Grund S, Wiltfang J. Early detection of oral cancer: dentists' opinions and practices before and after educational interventions in Northern-Germany. J Craniomaxillofac Surg. 2013;41(8):e201-7.

11. Alonge O, Narendran S. Opinions about oral cancer prevention and early detection among dentists practising along the Texas-Mexico border. Oral Dis. 2003;9(1):41-5. 
12. Carter LM, Ogden GR. Oral cancer awareness of undergraduate medical and dental students. BMC Med Educ. 2007;7:44.

13. Colella G, Gaeta GM, Moscariello A, Angelillo IF. Oral cancer and dentists: knowledge, attitudes, and practices in Italy. Oral Oncol. 2008;44(4):393-9.

14. Khattab NMA, Elheeny AAH, Tony GA. Oral-cancer knowledge, practice, and attitude assessment of dentists in Upper Egypt: a cross-sectional study. Clin Exp Dent Res. 2019:5(2):121-7.

15. Seoane-Lestón J, Velo-Noya J, Warnakulasuriya S, Varela Centelles P, Gonzalez-Mosquera A, Villa-Vigil M-A, et al. Knowledge of oral cancer and preventive attitudes of Spanish dentists. Primary effects of a pilot educational intervention. Med Oral Patol Oral Cir Bucal. 2010;15(3):e22-6.

16. Joseph BK, Sundaram DB, Sharma P. Oral cancer awareness among dentists in Kuwait. Med Princ Pract. 2012;21(2):164-70.

17. Kujan O, Duxbury AJ, Glenny AM, Thakker NS, Sloan P. Opinions and attitudes of the UK's GDPs and specialists in oral surgery, oral medicine and surgical dentistry on oral cancer screening. Oral Dis. 2006;12(2):194-9.

18. Kujan O, Alzoghaibi I, Azzeghaiby S, Altamimi MA, Tarakji B, Hanouneh S, et al. Knowledge and attitudes of Saudi dental undergraduates on oral cancer. J Cancer Educ. 2014;29(4):735-8.

19. Alaizari NA, Al-Maweri SA. Oral cancer: knowledge, practices and opinions of dentists in yemen. Asian Pac J Cancer Prev. 2014;15(14):5627-31.

20. Gaballah K, Faden A, Fakih FJ, Alsaadi AY, Noshi NF, Kujan O. Diagnostic accuracy of oral cancer and suspicious malignant mucosal changes among future dentists. Healthcare. 2021;9(3):263.

21. Kazmi F, Alkait S, Alghamdi H, Alhussain G, Tabassum A. Assessing knowledge, attitude and practices for oral squamous cell carcinoma among health care professionals in Princess Nourah University, Riyadh. KSA Asian Pac J Cancer Prev. 2020;21(2):539-45

22. Taheri JB, Namazi Z, Azimi S, Mehdipour M, Behrovan R, Rezaei Far K Knowledge of oral precancerous lesions considering years since graduation among dentists in the capital city of Iran: a pathway to early oral cancer diagnosis and referral? Asian Pac J Cancer Prev. 2018;19(8):2103-8. https://doi.org/10.22034/APJCP.2018.19.8.2103.

23. Diz P, Meleti M, Diniz-Freitas M, Vescovi P, Warnakulasuriya S, Johnson NW, et al. Oral and pharyngeal cancer in Europe: incidence, mortality and trends as presented to the Global Oral Cancer Forum. Transl Res Oral Oncology. 2017;2:66.

24. World Health Organization (WHO). Tobacco Control Fact Sheet-Republic of Moldova. 2016. https://www.euro.who.int/_data/assets/pdf_file/ 0006/312594/Tobacco-control-fact-sheet-RepofMoldova.pdf. Accessed 15 Nov 2021.

25. International Agency for Research on Cancer. Republic of MoldovaGlobal Cancer Observatory. 2020. https://gco.iarc.fr/today/data/facts heets/populations/498-republic-of-moldova-fact-sheets.pdf. Accessed 15 Nov 2021.

26. World Health Organization (WHO). Tobacco Control Fact Sheet-Belarus. 2017. https://www.euro.who.int/_data/assets/pdf_file/0010/337429/ Tobacco-Control-Fact-Sheet-Belarus.pdf. Accessed 15 Nov 2021.

27. International Agency for Research on Cancer. Belarus_-Global Cancer Observatory. 2020. https://gco.iarc.fr/today/data/factsheets/populations/ 112-belarus-fact-sheets.pdf. Accessed 15 Nov 2021.

28. World Health Organization (WHO). Tobacco Control Fact Sheet-Armenia. 2017. https://www.euro.who.int/ data/assets/pdf_file/0008/ 337418/Tobacco-Control-Fact-Sheet-Armenia.pdf. Accessed 15 Nov 2021.

29. International Agency for Research on Cancer. Armenia-Global Cancer Observatory. 2020. https://gco.iarc.fr/today/data/factsheets/populations/ 51-armenia-fact-sheets.pdf. Accessed 15 Nov 2021.

30. World Health Organization (WHO). Global status report on alcohol and health. Geneva: World Health Organization; 2018.

31. Hertrampf K, Wiltfang J, Koller M, Klosa K, Wenz HJ. Dentists' perspectives on oral cancer: a survey in Northern Germany and a comparison with international data. Eur J Cancer Prev. 2010;19(2):144-52.

32. Tseveenjav B, Vehkalahti M, Murtomaa H. Oral health and its determinants among Mongolian dentists. Acta Odontol Scand. 2004;62(1):1-6.
33. Allen K, Farah CS. Screening and referral of oral mucosal pathology: a check-up of Australian dentists. Aust Dent J. 2015;60(1):52-8.

34. Kebabcioglu O, Pekiner FN. Assessing oral cancer awareness among dentists. J Cancer Educ. 2018;33(5):1020-6.

35. Ter-Poghosyan $H$, Nalbandyan M. Systems for the provision of oral health care in the Black Sea countries. Part 4: Armenia. Oral Health Dent Manag. 2010;9(1):3-6.

36. Ciobanu S, Godoroja P, Lupan I, Pancenco A. Systems for the provision of oral health care in Black Sea countries. Part 3: Moldova. Oral Health Dent Manag. 2009;8(4):3-5

37. Tserakhava T, Shakavets N, Smirnoy A. Systems for the provision of oral health care in the Black Sea Countries. Part 9: Belarus. Oral Health Dent Manag. 2011;10(3):115-8.

38. Rumgay $\mathrm{H}$, Shield $\mathrm{K}$, Charvat $\mathrm{H}$, Ferrari $\mathrm{P}$, Sornpaisarn $\mathrm{B}$, Obot I, et al. Global burden of cancer in 2020 attributable to alcohol consumption: a population-based study. Lancet Oncol. 2021;22(8):1071-80.

39. Menezes FDS, Fernandes GA, Antunes JLF, Villa LL, Toporcov TN. Global incidence trends in head and neck cancer for HPV-related and -unrelated subsites: a systematic review of population-based studies. Oral Oncol. 2021;115:105177.

40. Melo BAC, Vilar LG, Oliveira NR, Lima PO, Pinheiro MB, Domingueti CP, et al. Human papillomavirus infection and oral squamous cell carcinoma-a systematic review. Braz J Otorhinolaryngol. 2021;87(3):346-52.

41. Messadi DV. Diagnostic aids for detection of oral precancerous conditions. Int J Oral Sci. 2013;5(2):59-65.

42. Canto MT, Drury TF, Horowitz AM. Maryland dentists' knowledge of oral cancer risk factors and diagnostic procedures. Health Promot Pract. 2001;2(3):255-62.

43. Neville BW, Day TA. Oral cancer and precancerous lesions. CA Cancer J Clin. 2002;52(4):195-215.

44. Warnakulasuriya S, Kujan O, Aguirre-Urizar JM, Bagan JV, González-Moles MÁ, Kerr AR, et al. Oral potentially malignant disorders: A consensus report from an international seminar on nomenclature and classification, convened by the WHO Collaborating Centre for Oral Cancer. Oral Dis. 2021;27(8):1862-80.

45. Scully C, Shotts R. Mouth ulcers and other causes of orofacial soreness and pain. West J Med. 2001;174(6):421-4.

46. Ahmed NHM, Naidoo S. Oral cancer knowledge, attitudes, and practices among dentists in Khartoum State, Sudan. J Cancer Educ. 2019:34(2):291-6.

47. Razavi SM, Zolfaghari B, Foroohandeh M, Doost ME, Tahani B. Dentists' knowledge, attitude, and practice regarding oral cancer in Iran. J Cancer Educ. 2013;28(2):335-41.

48. Hashim R, Abo-Fanas A, Al-Tak A, Al-Kadri A, Abu EY. Early detection of oral cancer-dentists' knowledge and practices in the United Arab Emirates. Asian Pac J Cancer Prev. 2018;19(8):2351-5.

49. Shugars DC, Patton LL. Detecting, diagnosing, and preventing oral cancer. Nurse Pract. 1997;22(6):66.

50. Patton LL, Elter JR, Southerland JH, Strauss RP. Knowledge of oral cancer risk factors and diagnostic concepts among North Carolina dentists: implications for diagnosis and referral. J Am Dent Assoc. 2005;136(5):602-10

51. Hassona Y, Sawair F, Baqain Z, Maayta W, Shahin A, Scully C Oral cancer early detection-a pressing need for continuing education in Jordan. Asian Pac J Cancer Prev. 2015;16(17):7727-30.

52. Asch DA, Jedrziewski MK, Christakis NA. Response rates to mail surveys published in medical journals. J Clin Epidemiol. 1997:50(10):1129-36.

\section{Publisher's Note}

Springer Nature remains neutral with regard to jurisdictional claims in published maps and institutional affiliations. 